\title{
Effect of Sea Salt and Taro Waste on Fungal Mortierella alpina Cultivation for Arachidonic Acid-Rich Lipid Production
}

\author{
Yen-Hui Chen *, Chang-Chng Ong (D) and Ting-Yao Lin
}

check for updates

Citation: Chen, Y.-H.; Ong, C.-C.; Lin, T.-Y. Effect of Sea Salt and Taro Waste on Fungal Mortierella alpina Cultivation for Arachidonic Acid-Rich Lipid Production. Fermentation 2022, 8, 81 . https://doi.org/10.3390/ fermentation 8020081

Academic Editor: Diomi Mamma

Received: 25 January 2022

Accepted: 13 February 2022

Published: 16 February 2022

Publisher's Note: MDPI stays neutral with regard to jurisdictional claims in published maps and institutional affiliations.

Copyright: (C) 2022 by the authors. Licensee MDPI, Basel, Switzerland. This article is an open access article distributed under the terms and conditions of the Creative Commons Attribution (CC BY) license (https:// creativecommons.org/licenses/by/ $4.0 /)$.

\author{
Department of Food Science, National Ilan University, Number 1, Section 1, Shen-Lung Road, Yilan City 260 , \\ Taiwan; eric-ong93@hotmail.com (C.-C.O.); g840812@gmail.com (T.-Y.L.) \\ * Correspondence: yenhui@niu.edu.tw; Tel.: +886-393-17-753
}

\begin{abstract}
Arachidonic acid (ARA), an important polyunsaturated fatty acid (PUFA), acts as a precursor for eicosanoid hormones, such as prostaglandins, leukotrienes and other biological substances in human and animal bodies. Mortierella alpina is considered to be a potential strain for ARA production. Using agricultural waste as a substrate for microbial fermentation could achieve biorefinery concepts, and sea water utilization of the cultivation process could help to conserve fresh water resources. The objectives of this study were to find a potential M. alpina strain for ARA production, to investigate the tolerance of salinity and to evaluate the feasibility of the taro waste hydrolysate for M. alpina cultivation. The result showed that M. alpina FU30797 had the highest lipid content (25.97\%) and ARA ratio (34.60\%) among three strains. Furthermore, there was no significant difference between 0 and $10 \mathrm{~g} / \mathrm{L}$ of sea salt solution on the biomass concentration and lipid content of M. alpina FU30797. The acidic hydrolysate and enzymatic hydrolysate of taro peel waste (TPW) were both utilized as culture substrates by M. alpina FU30797; however, the substrate up-take rate and lipid content in the TPW enzymatic hydrolysate cultivation were $292.33 \mathrm{mg} / \mathrm{L}-\mathrm{h}$ and $30.68 \%$, respectively, which are higher than those in acidic hydrolysate cultivation, and the ARA ratio was $33.05 \%$ in the enzymatic hydrolysate cultivation. From fed-batch cultivation in the bioreactor, the lipid content and ARA ratio reached $36.97 \%$ and $46.04 \%$, respectively. In summary, the results from this project could potentially provide useful information for developing the PUFA-ARA bioprocess by using M. alpina.
\end{abstract}

Keywords: Mortierella alpina; arachidonic acid; lipid; sea salt; taro waste

\section{Introduction}

Polyunsaturated fatty acids (PUFAs) are important to membrane phospholipids as structural components, and to eicosanoids as precursors. Eicosanoids play critical roles in immune response, inflammatory reactions, and the control of blood pressure [1]. Arachidonic acid (ARA; 5,8,11,14-cis-eicosatetraenoic acid, C20:4), one of the three essential fatty acids, is an important fatty acid of the omega- 6 series PUFA. ARA could be applied for the treatment of heart disease and cancer, and it is also the precursor of some physiologically hormones, such as prostaglandins and leukotrienes in mammals. Therefore, ARA is commonly used in the food/nutraceutical and medicine industries [2,3]. Conventional sources for ARA production are animal organs (pig adrenal glands), egg yolk and deep-sea fish; however, for the scale-up to industrial production, conventional sources are limited, due to undesirable characteristics, such as unacceptable flavor, low ARA content and seasonal restrictions $[4,5]$. With the increase in demand for ARA, alternative and sustainable sources for ARA production must be found.

Compared with conventional lipid production from plant and animal sources, microbial lipid production by oleaginous microorganisms has several advantages, including a higher growth rate, higher lipid content and less land demand. The Mortierella genus, filamentous fungi, has been considered as a potential strain for ARA production. In particular, Mortierella alpina, an oleaginous zygomycete, is used for ARA-rich lipid production [6]. 
Furthermore, ARA production from M. alpina received GRAS status from the US FDA in 2001 [6,7]. Research on the ARA production of M. alpina mainly focuses on the screening of strains, the lipid metabolic pathway, the optimization of culture conditions, and the separation and purification of ARA. Moreover, it has been reported that $\mathrm{pH}$, temperature, agitation, and medium composition (carbon source, nitrogen source, sodium chloride, or supplement) could affect the mycelia growth and fatty acid composition of its body [6,8-11].

Sustainable development, to produce biomaterials by applying bioconversion to various cheap biowastes, has attracted much attention, and it could achieve biorefinery concepts. Taro (Colocasia esulenta) is a tropical perennial, mainly grown in tropical and subtropical regions. In Asia, taro is used to produce a variety of desserts, such as taro pastry and fired taro ball. Taro peel, the abundant agricultural waste, contains starchy and cellulosic polysaccharides, which are great feedstock for microbial fermentation [12]. Starch-rich agricultural wastes have been reported as a carbon source for bioethanol production [13-15].

The objectives of this project were to investigate the fermentation parameters of $M$. alpina cultivation for PUFA-ARA production, by using agricultural wastes-taro peel waste (TPW) - and to evaluate the potential of sea salt medium, in order to conserve water resources. To the best of our knowledge, the current study is the first report on the potential of partial sea salt water replacement and TPW hydrostats into ARA using M. alpina.

\section{Materials and Methods}

\subsection{Microorganism and Culture Condition}

\subsubsection{Strain Maintenance and Inoculum Preparation}

Three strains of Mortierella alpina were used in this study, and BCRC 32738, BCRC FU30797, and BCRC FU30281 were obtained from Bioresource Collection and Research Center (BCRC, Hsinchu City, Taiwan), and maintained on potato dextrose agar (PDA) plates and transferred every two weeks. A quantity of $3 \times 1 \mathrm{~cm}^{2}$ of culture grown on PDA plate was inoculated into $100 \mathrm{~mL}$ inoculum medium containing the following $(\mathrm{g} / \mathrm{L})$ : glucose 20.0, yeast extract 30.0, $\mathrm{KH}_{2} \mathrm{PO}_{4} 0.2$ incubated for $48 \mathrm{~h}$ at $25^{\circ} \mathrm{C}$ under constant orbital shaking at $200 \mathrm{rpm}$ [16].

\subsubsection{Strain Selection}

M. alpina (32738, FU30797; FU30281) cultivated pellet was homogenized with HG$300 \mathrm{D}$ homogenizer for $10 \mathrm{~s}$ at $100 \mathrm{rpm}$. An amount of $5 \mathrm{~mL}(10 \%, v / v)$ mycelial suspension was inoculated in $45 \mathrm{~mL}$ fermentation media containing the following $(\mathrm{g} / \mathrm{L})$ : glucose 20.0, yeast extract 8.0, $\mathrm{KH}_{2} \mathrm{PO}_{4} 0.2, \mathrm{MgSO}_{4} 0.5$ and incubated at $25^{\circ} \mathrm{C}$ and $200 \mathrm{rpm}$ for $120 \mathrm{~h}$ for further biomass concentration, lipid content and fatty acid composition analyses [17].

\subsubsection{Artificial Sea Salt: Batch Cultivation in the Shaker Flask}

M. alpina FU30797 10\% $(v / v)$ mycelial suspension was inoculated in $45 \mathrm{~mL}$ fermentation media containing the following $(\mathrm{g} / \mathrm{L})$ : glucose 40.0 , yeast extract 8.0, $\mathrm{KH}_{2} \mathrm{PO}_{4} 0.2$, $\mathrm{MgSO}_{4}$ 0.5, with 0, 10, 30, 50, 70 and $90 \mathrm{~g} / \mathrm{L}$ artificial sea salt solution (as-prepared artificial seawater), and then incubated at $25^{\circ} \mathrm{C}$ and $200 \mathrm{rpm}$ for $120 \mathrm{~h}$ for further biomass concentration, lipid content and ARA ratio analyses.

\subsubsection{TPW Hydrolysate: Batch Cultivation in the Shaker Flask}

M. alpina FU30797 10\% $(v / v)$ mycelial suspension was inoculated in $45 \mathrm{~mL}$ fermentation media containing the following $(\mathrm{g} / \mathrm{L})$ : TPW acid or enzymatic hydrolysate (carbon substrate as glucose) 40.0 , yeast extract $8.0, \mathrm{KH}_{2} \mathrm{PO}_{4} 0.2, \mathrm{MgSO}_{4} 0.5$ and incubated at $25^{\circ} \mathrm{C}$ and $200 \mathrm{rpm}$ for $120 \mathrm{~h}$ for further biomass concentration, lipid content and ARA ratio analyses.

\subsubsection{TPW Hydrolysate: Batch and Fed-Batch Cultivation in the Bioreactor}

Batch and fed-batch fermentations were carried out in a $5 \mathrm{~L}$ bioreactor equipped with two six-flat-bladed Rushton impellers. For batch cultivation, the basal fermentation 
medium contained the following (g/L): carbon substrate (as glucose) 40.0, yeast extract 8.0, $\mathrm{KH}_{2} \mathrm{PO}_{4}$ 0.2, $\mathrm{MgSO}_{4}$ 0.5, and the initial growth medium was $1.8 \mathrm{~L}$. M. alpina FU30797 inoculum was prepared as described in the previous section, and the inoculum size was $10 \%(v / v)$. Temperature was controlled at $25^{\circ} \mathrm{C}$ by electrical heating and water cooling. The agitation speed was set at $200 \mathrm{rpm}$ and the aeration rate was set at $3 \mathrm{~L} / \mathrm{min}$. Total cultivation time was $120 \mathrm{~h}$, and samples were taken at intervals for further analysis. For fed-batch fermentation, the conditions of the basal fermentation medium, inoculum preparation, inoculum size, temperature, initial aeration rate and agitation speed were the same as those of the batch fermentation. The stock solution contained the following $(\mathrm{g} / \mathrm{L})$ : carbon substrate (as glucose) 100.0, yeast extract 20.0, $\mathrm{KH}_{2} \mathrm{PO}_{4} 0.2, \mathrm{MgSO}_{4} 0.5$, and it was added into the culture medium to maintain the glucose concentration at 10-20 g/L. To maintain dissolved oxygen (DO), the aeration rate was set at $5 \mathrm{~L} / \mathrm{min}$ for $20 \mathrm{~h}$, and agitation speed was increased by $10 \mathrm{rpm}$ at 20,22, 28, 35, $54 \mathrm{~h}$. Total cultivation time was $144 \mathrm{~h}$, samples were taken at intervals for determination of biomass concentration, substrate (as glucose) consumption, lipid content and ARA ratio. $\mathrm{DO}, \mathrm{pH}$ and temperature were recorded by Suntex DLT Data Logger (Suntex Instruments, New Taipei City, Taiwan).

\subsection{Acidic and Enzymatic Hydrolysis of Taro Peel Waste (TPW Acidic and Enzymatic Hydrolysate Preparation)}

Taro peel waste (TPW) was kindly provided by Yih Shun Shiuan Company (Yi-Lan, Taiwan). TPW was ground and then sieved by \#20 mesh. TPW sample was stored at $-20{ }^{\circ} \mathrm{C}$ for further experiments. Acidic hydrolysis procedure was modified from the previous study [18], sulfuric acid 3.21\%, temperature $93.8^{\circ} \mathrm{C}$ and $4.13 \mathrm{~h}$ for optimizing the reduction of sugar concentration of hydrolysate. Enzymatic hydrolysis procedure was modified from the previous study [19], and $\alpha$-amylase dosage $7 \mathrm{~mL}$, temperature $52.5^{\circ} \mathrm{C}$ and time $2 \mathrm{~h}$ were applied for liquefaction. The mixture was agitated at $125 \mathrm{rpm}$ in a shaker water bath. In the saccharification, amyloglucosidase dosage $50 \mu \mathrm{L}$, temperature $56.7^{\circ} \mathrm{C}$ and time $3 \mathrm{~h}$ were used.

\subsection{Analytical Procedure}

The biomass concentration was measured as dried weight $\left(50^{\circ} \mathrm{C}\right.$, oven overnight) [20]. The carbon substrate (as glucose) of the culture medium was measured by the 3,5-dinitrosalicylic acid (DNS) method. The DNS color tests were conducted with $3 \mathrm{~mL}$ of dinitrosalicylic acid reagent added to $3 \mathrm{~mL}$ of glucose solution in tubes. The mixtures were heated for $10 \mathrm{~min}$ in a boiling water bath then cooled to ambient temperature. The color intensities were measured in a spectrophotometer at $575 \mathrm{~nm}$ [21]. The lipid content was analyzed by the Soxhlet method with n-hexane as extraction solvent [16]. The analytical procedure of fatty acid composition was modified from the Method of Test for Fatty Acids in Food-MOHWO0014.00 (Food and Drug Administration, Taipei City, Taiwan). About 10-20 mg of lipid samples were weighted into a test tube, and then $0.1 \mathrm{~mL}$ of internal standard (triheneicosanoin, 21:0; Nu-Chek Prep, Elysian, MN, USA) was added. Aliquots were dissolved with $1 \mathrm{~mL}$ of $\mathrm{n}$-hexane. $1 \mathrm{~mL}$ of $1 \mathrm{~N}$ sodium hydroxide in methanol and $1 \mathrm{~mL}$ of $14 \%$ boron trifluoride in methanol were used for saponification and esterification. Sample was extracted by mixing with $1 \mathrm{~mL}$ of $\mathrm{n}$-hexane for $1 \mathrm{~min}$, and then $6 \mathrm{~mL}$ of saturated sodium chloride solution was added. The upper layer was placed into a vial, and a small quantity of sodium sulfate anhydrous was added, then filtered with a membrane filter, and the filtrate was taken as the sample solution. Identification and quantification were performed by using gas chromatograph (Clarus ${ }^{\circledR} 680$, Perkin Elmer, Waltham, MA, USA) with a flame ionization detector and a $100 \mathrm{~m} \mathrm{HP-88} \mathrm{capillary} \mathrm{column}$ $(0.25 \mathrm{~mm}$ i.d. and $0.20 \mu \mathrm{m}$ film thickness). Column temperature was programmed to be held at $170{ }^{\circ} \mathrm{C}$ for $40 \mathrm{~min}$, and then increase to $200^{\circ} \mathrm{C}$ at $3^{\circ} \mathrm{C}$ per min and held for $50 \mathrm{~min}$. The injector and detector were maintained at $250{ }^{\circ} \mathrm{C}$ and $300{ }^{\circ} \mathrm{C}$, respectively. Sample injection volume was $1.0 \mu \mathrm{L}$. Nitrogen was the carrier gas at a flow rate of $0.75 \mathrm{~mL}$ per min with a split ratio of 1:40. Quantification of individual fatty acid methyl esters was accomplished by incorporating a known amount and peak area of internal standard. Peaks were identified by comparing 
the retention time to reference standards of 37 components of FAME mix (Supelco, Bellefonte, PA, USA).

\subsection{Statistical Analysis}

The significance level was set at 0.05 for one-way analysis of variance and Duncan's multiple comparison of treatment mean by using Statistical Package for the Social Sciences 18.0.

\section{Results and Discussion}

\subsection{Strain Selection}

The biomass concentration, lipid content, and ARA ratio of total fatty acids may vary among strains, even under the same culture conditions. A suitable strain is the crucial key to sustainably developing the upper-stream bioprocess of ARA production by $M$. alpina. In this study, three potential M. alpina strains (32738, FU30281, and FU30797) were chosen to evaluate the biomass concentration, lipid content and ARA content. M. alpina FU30281 is a Taiwanese indigenous strain, which is found in Alishan, Chiayi. As shown in Table 1, the biomass concentrations of 32738, FU30281 and FU30797 were 8.95, 8.80 and $8.49 \mathrm{~g} / \mathrm{L}$, respectively, with glucose as the substrate, and there was no significant difference between the three strains $(p<0.05)$. However, $M$. alpina FU30797 had the highest lipid content (25.97\%), ARA ratio (34.6\%) and lipid production (2.2 g/L) among the three strains. The fatty acid composition analysis of M. alpina FU30797 is shown in Figure 1; it contained palmitic acid (C16:0) 12.32\%, stearic acid (C18:0) $15.86 \%$, oleic acid (C18:1) 17.16\%, linoleic acid (C18:2) 7.92\%, linolenic acid (C18:3) 4.93\%, eicosatrienoic acid (C20:3) 3.17\%, and arachidonic acid (C20:4) 34.6\%. The polyunsaturated fatty acids (PUFAs) ratio and monounsaturated fatty acids (MUFAs) ratio of M. alpina FU30797 were $51.97 \%$ and $18.03 \%$, respectively, which indicated that the lipid of M. alpina FU30797 was a good unsaturated fatty acid food source.

Table 1. Biomass concentration, lipid content, lipid production and ARA ratio of different Mortierella alpina strains.

\begin{tabular}{ccccc}
\hline $\begin{array}{c}\text { Mortierella } \\
\text { alpina }\end{array}$ & $\begin{array}{c}\text { Biomass Conc. } \\
\text { (g/L) }\end{array}$ & $\begin{array}{c}\text { Lipid Content } \\
(\mathbf{\%})\end{array}$ & $\begin{array}{c}\text { Lipid } \\
\text { Production } \\
\text { (g/L) }\end{array}$ & $\begin{array}{c}\text { ARA Ratio (\% } \\
\text { of TFAs) }\end{array}$ \\
\hline 32738 & $8.95 \pm 2.33^{\mathrm{a}}$ & $11.01 \pm 0.02^{\mathrm{b}}$ & $1.21 \pm 0.11^{\mathrm{b}}$ & $30.22 \pm 0.54^{\mathrm{a}}$ \\
FU30281 & $8.80 \pm 0.11^{\mathrm{a}}$ & $6.92 \pm 0.02^{\mathrm{b}}$ & $0.91 \pm 0.25^{\mathrm{b}}$ & $15.30 \pm 0.54^{\mathrm{b}}$ \\
FU30797 & $8.49 \pm 1.46^{\mathrm{a}}$ & $25.97 \pm 2.34^{\mathrm{a}}$ & $2.20 \pm 0.03^{\mathrm{a}}$ & $34.60 \pm 3.54^{\mathrm{a}}$ \\
\hline
\end{tabular}

$\overline{\mathrm{a}, \mathrm{b}}$ Means with different superscript in the same column were significantly different $(p<0.05)$. Initial glucose concentration was $20 \mathrm{~g} / \mathrm{L}$.

Fungal morphology is considered to be one of the major parameters in the industrial fermentation process. The ARA accumulation of $M$. alpina occurs through enzymatic desaturation, which may include oxygenation, and an adequate dissolved oxygen level is obtained by a suitable agitation speed, aeration rate and gas composition. The shear stress from agitation and medium composition might affect the fungal morphology of $M$. alpina. In addition, the physical properties, such as mass/heat transfer, gas dispersion and homogenization of the cultivation broth, were influenced by the growth of M. alpina. Therefore, it is important to find the optimal fungal morphology of $M$. alpina for ARA production. The morphology observation is shown in Figure 2. M. alpina 32,738 and FU30281 were filament-like structures (hyphal filaments), but M. alpina FU30797 was a small pellet-like structure (red arrow in Figure 2Bc), which was suitable for suspension cultivation. Even though feather-like hyphae could obtain a higher ARA content at a low biomass concentration (because hyphae have easier access to nutrients and gas exchange in the culture medium), this morphology is not suitable for M. alpina growth at a high biomass concentration, because the growth of hyphae tends to increase the viscosity of the medium at high biomass concentrations, and this makes the agitation of the medium more difficult, 
which might affect nutrient accessibility and the dissolved oxygen level. Higashiyama et al. reported that a higher hyphae content would increase the apparent viscosity, which could affect mass and oxygen transfer, and a larger cell pellet might not be suitable for cell growth, due to the nutrient transfer limitation through the pellet wall [22]. Therefore, due to it obtaining the highest lipid content, ARA ratio and lipid production, with an adequate cell morphology, M. alpina FU30797 was selected for further experiments to evaluate the potential use of sea salt as a medium and the feasibility of the TPW hydrolysate for ARA production.

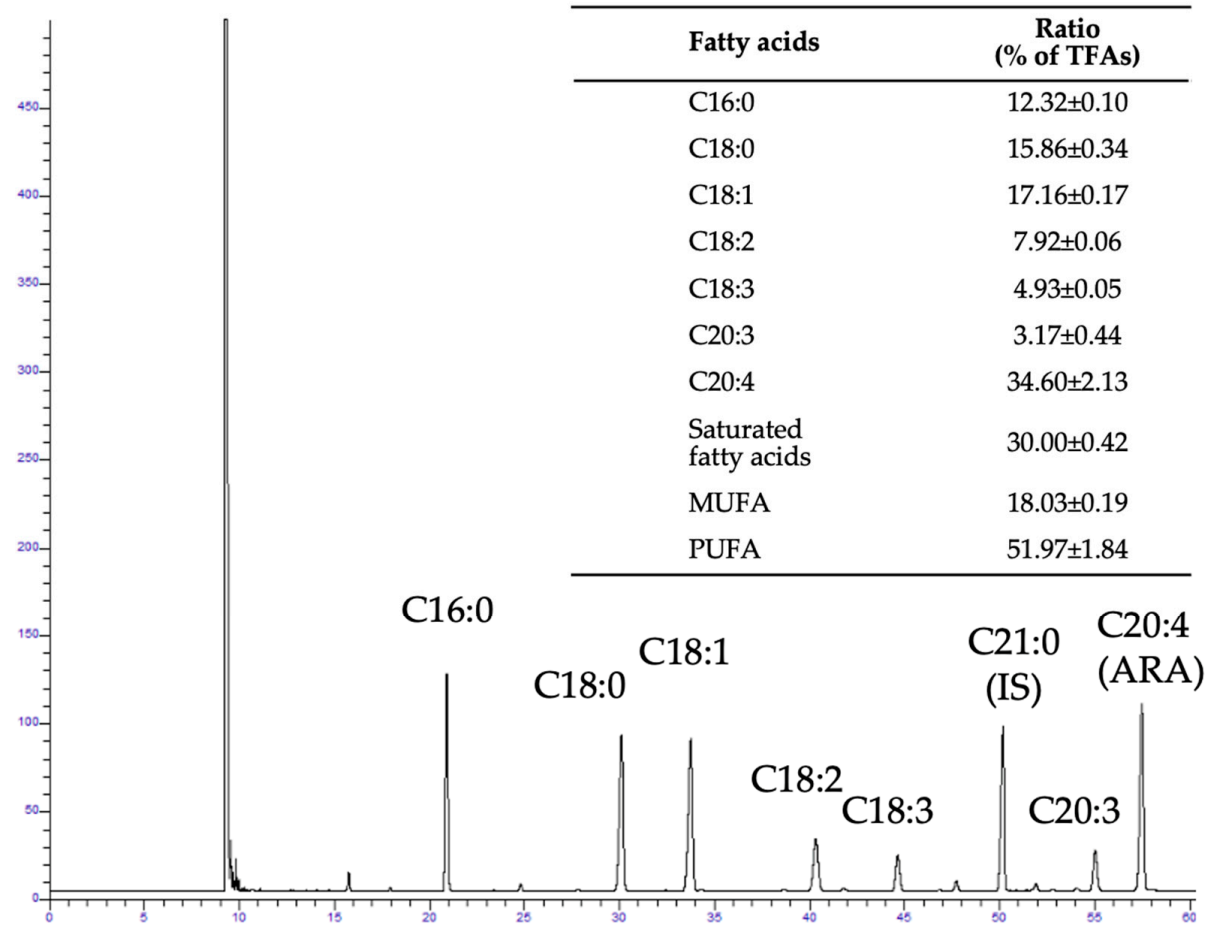

Figure 1. Total Fatty acid profile of M. alpina FU30797 after 5 days of cultivation.

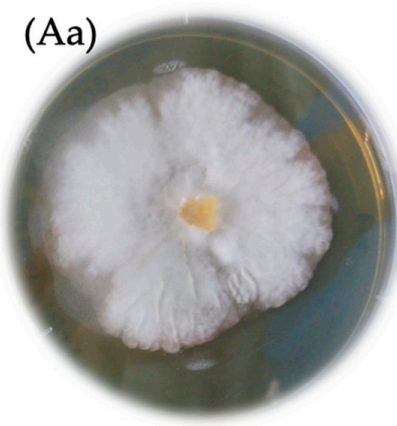

(Ba)

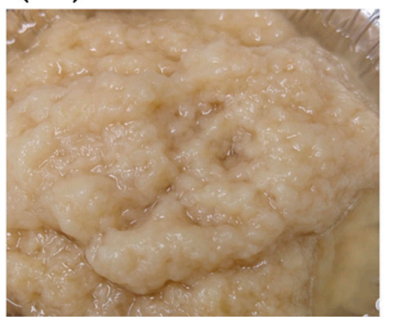

$(\mathrm{Ab})$

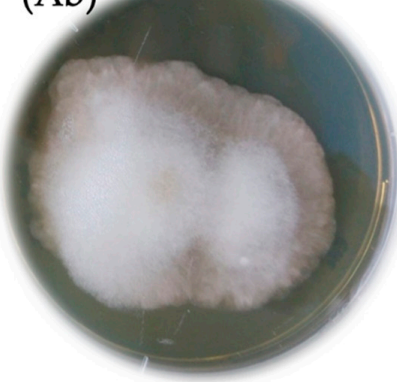

$(\mathrm{Bb})$

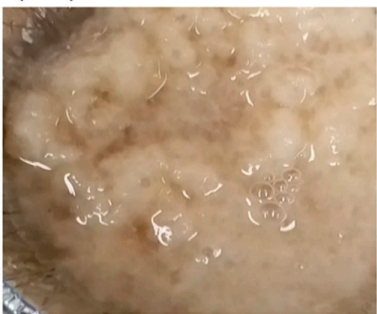

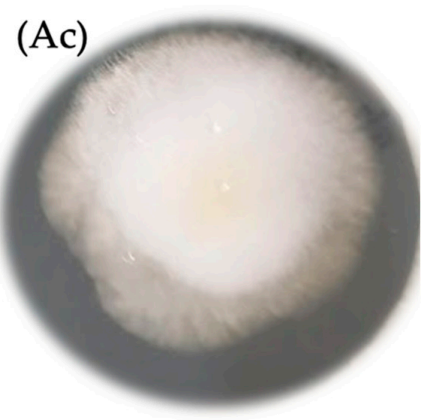

(Bc)

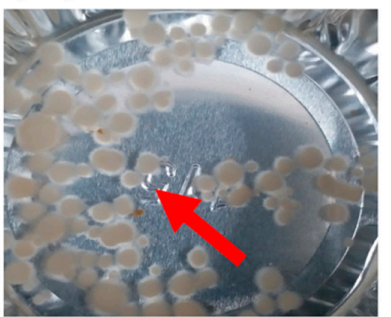

Figure 2. Morphology of Mortierella alpina (a. 32738, b. FU30281, c. FU30797): (A) in plate and (B) biomass from suspension cultivation. 


\subsection{The Tolerance of Salinity}

For the sustainable and economic cultivation of microorganisms, the concept of replacing partial fresh water with seawater was promoted. Furthermore, M. alpina could grow in salt marshes, and it is important to investigate the tolerance of M. alpina FU30797 to salinity. In this study, M. alpina FU30797 was cultivated in different artificial sea salt solutions, with $40 \mathrm{~g} / \mathrm{L}$ glucose as a carbon substrate. The results found that M. alpina FU30797 could not grow in more than $90 \mathrm{~g} / \mathrm{L}$ of artificial sea salt solution (data not shown). As shown in Table 2, M. alpina FU30797 has tolerance to the artificial sea salt solution up to $30 \mathrm{~g} / \mathrm{L}$, with no significant difference in biomass concentration, but the lipid content was slightly lower than $30 \%$ at $30 \mathrm{~g} / \mathrm{L}$ of sea salt solution. Ho et al. reported that $M$. alpina SC9 could grow in $4 \% \mathrm{NaCl}$ medium, and PUFAs could account for over $50 \%$ of the total fatty acids (TFAs) of the cells in the cultures with a $\mathrm{NaCl}$ concentration up to $2 \%$ [23]. In addition, diacylglycerol acyltransferase 2 (DGAT2), the gene expression level of TAG biosynthesis, was higher in the $\mathrm{NaCl}$-treated cells [23]. Song et al. used different fermentation-associated wastewater percentages $(100 \%, 75 \%, 50 \%, 25 \%$, and $12.5 \%)$ to replace the fresh water in the medium for cultivating M. alpina SD003, and the results found that the ARA yields were significantly inhibited when the wastewater from the fermentation process was directly reused. The lowest biomass and ARA yield in the treatment group were 19.7 and $3.01 \mathrm{~g} / \mathrm{L}$ respectively, which are slightly lower than those of the control group [24]. These studies indicated the effect of $\mathrm{NaCl}$ and wastewater on fatty acid production by M. alpina, and different strains may show distinct levels of tolerance. In Figure 3, the fungal mycelium of M. alpina FU30797 became larger by increasing the concentration from 0 to $50 \mathrm{~g} / \mathrm{L}$ (Figure $3 \mathrm{~A}-\mathrm{D}$ ), but the opposite result was found between 70 and $90 \mathrm{~g} / \mathrm{L}$. The maximum substrate consumption $(231.6 \mathrm{~g} / \mathrm{h})$ and lipid content $(30.99 \%)$ were found in the concentration of $10 \mathrm{~g} / \mathrm{L}$, and the ARA ratio was $34.02 \%$.

Table 2. Biomass concentration and lipid content of Mortierella alpina FU30797 in different artificial sea salt concentrations.

\begin{tabular}{ccc}
\hline Artificial Sea Salt (g/L) & Biomass Conc. (g/L) & Lipid Content (\%) \\
\hline 0 & $17.96 \pm 0.13^{\mathrm{a}}$ & $30.60 \pm 1.84^{\mathrm{a}}$ \\
10 & $16.86 \pm 0.38^{\mathrm{a}}$ & $30.99 \pm 0.74^{\mathrm{a}}$ \\
30 & $16.35 \pm 1.59^{\mathrm{a}}$ & $26.10 \pm 0.59^{\mathrm{b}}$ \\
50 & $11.73 \pm 1.18^{\mathrm{b}}$ & $24.80 \pm 1.36^{\mathrm{b}}$ \\
70 & $8.63 \pm 3.38^{\mathrm{b}, \mathrm{c}}$ & $18.43 \pm 2.39^{\mathrm{c}}$ \\
90 & $9.46 \pm 0.96^{\mathrm{c}}$ & $11.26 \pm 2.15^{\mathrm{d}}$ \\
\hline
\end{tabular}

${ }^{a-d}$ Means with different superscript in the same column were significantly different $(p<0.05)$. Initial glucose concentration was $40 \mathrm{~g} / \mathrm{L}$.

\subsection{The Feasibility of TPW Hydrolysate as Carbon Substrate for M. alpina Cultivation}

In order to use agro-waste for microbial cultivation, different hydrolysis methods, such as heat, base/acid and enzyme, must be applied to convert it from a large molecular mass to a small sugar. To evaluate the feasibility of the enzymatic and acidic hydrolysate from the TPW, M. alpina FU30797 was cultivated under a carbon substrate (as glucose), with a concentration of $40 \mathrm{~g} / \mathrm{L}$, in the shaker flask for 5 days. In Figure 4 , the results indicate that there was a lag phase in the first day of both hydrolysate fermentations, and M. alpina FU30797 could utilize both enzymatic and acidic hydrolysate as carbon substrates; however, the substrate consumption rate of enzymatic hydrolysate fermentation was $292.33 \mathrm{mg} / \mathrm{L}-\mathrm{h}$, which is higher than that in acidic hydrolysate fermentation. The ARA ratios of enzymatic and acidic hydrolysate fermentations were similar $(33.05 \%$ and $34.58 \%$, respectively), but the biomass concentration and lipid content were higher in enzymatic hydrolysate fermentations, and these could reach $16.79 \mathrm{~g} / \mathrm{L}$ and $30.68 \%$, respectively, after 5 days of cultivation (Table 3). This inhibition of acidic hydrolysate fermentations may be due to by-products (such as 5-hydroxymethylfurfural) from acid hydrolysis and salts from medium neutralization before fermentation [14]. Mamani et al. used potato waste 
hydrolysate (60 $\mathrm{g} / \mathrm{L}$ reducing sugar) as a carbon source, with different nitrogen sources, for M. alpina fermentation, and the ARA ratios were around 35\% [25], and the results are similar to our results. Furthermore, they reported a $7 \%$ saving in culture media expenses by using potato waste hydrolysate, compared to the conventional synthetic culture medium [25]. Due to a higher biomass concentration, lipid content and ARA ratio, enzymatic hydrolysate was selected for further batch and fed-batch scale-up bioreactor experiments.
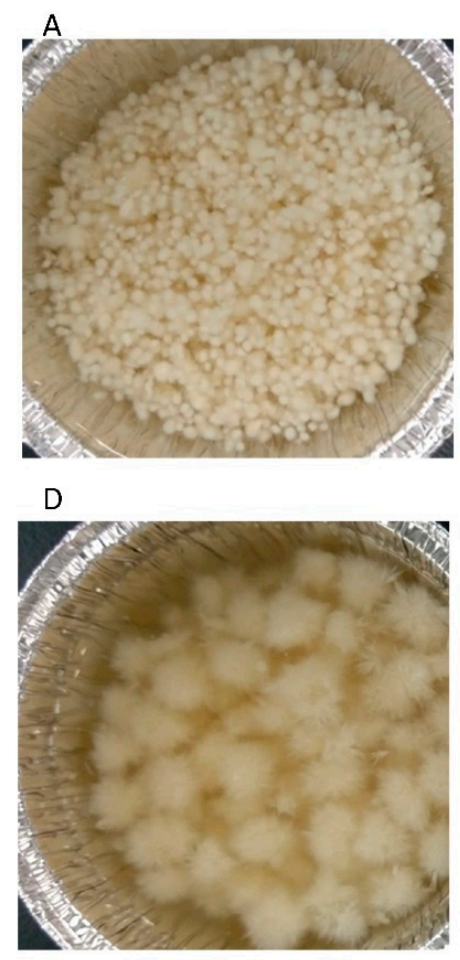

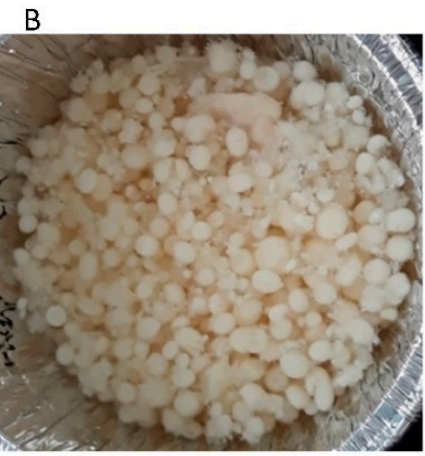

E

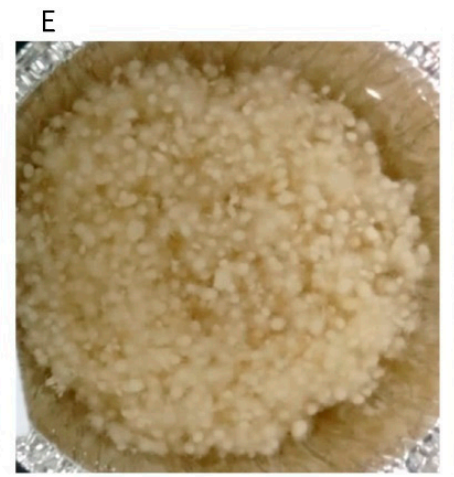

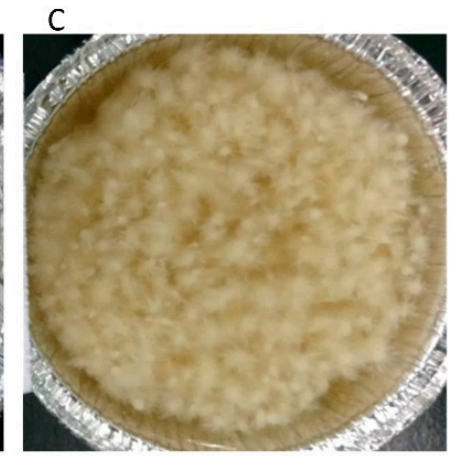

$\mathrm{F}$

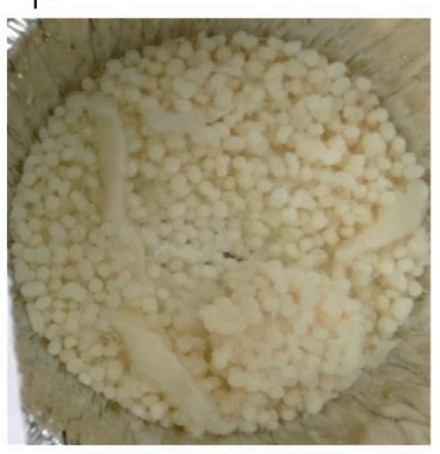

Figure 3. Morphology of Mortierella alpina FU30797 after 5 days of cultivation in different artificial sea salt concentrations. (A) $0 \mathrm{~g} / \mathrm{L}$; (B) $10 \mathrm{~g} / \mathrm{L}$; (C) $30 \mathrm{~g} / \mathrm{L}$; (D) $50 \mathrm{~g} / \mathrm{L}$; (E) $70 \mathrm{~g} / \mathrm{L}$; (F) $90 \mathrm{~g} / \mathrm{L}$.
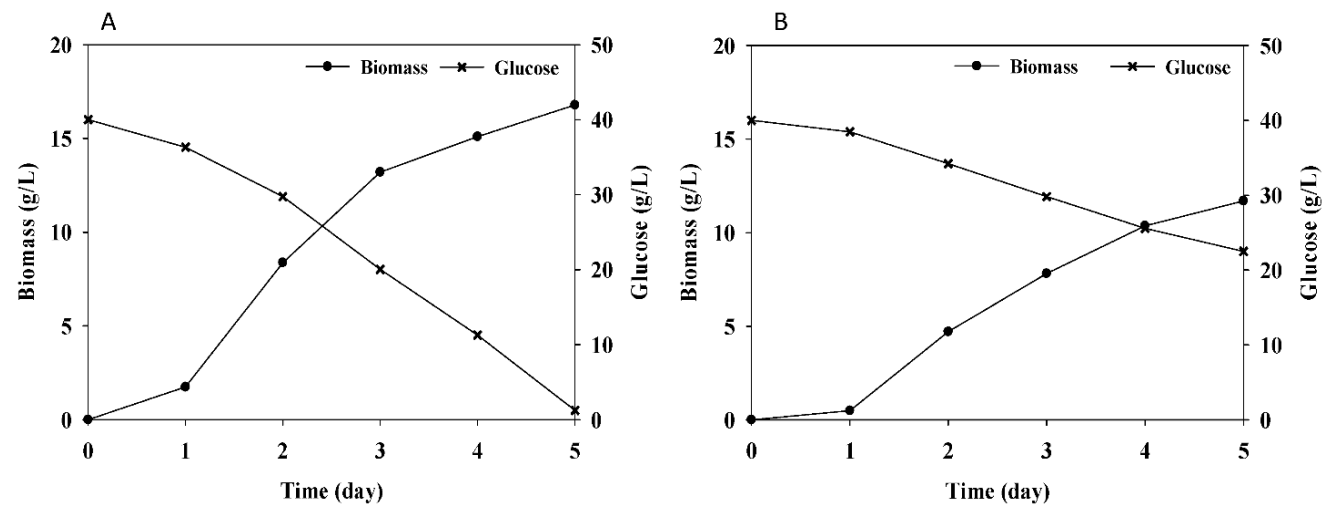

Figure 4. Biomass concentration and glucose consumption of Mortierella alpina FU30797 with TPW hydrolysate in the shake flask. (A) enzymatic hydrolysate, (B) acidic hydrolysate (initial glucose concentration was $40 \mathrm{~g} / \mathrm{L}$ ). 
Table 3. Biomass concentration, lipid content, lipid production and ARA ratio of Mortierella alpina FU30797 after 5 days of cultivation with TPW acidic and enzymatic hydrolysate.

\begin{tabular}{ccccc}
\hline Substrate & $\begin{array}{c}\text { Biomass Conc. } \\
\mathbf{( g / L )}\end{array}$ & $\begin{array}{c}\text { Lipid Content } \\
\mathbf{( \% )}\end{array}$ & $\begin{array}{c}\text { Lipid } \\
\text { Production }(\mathbf{g} / \mathrm{L})\end{array}$ & $\begin{array}{c}\text { ARA Ratio (\% } \\
\text { TFAs) }\end{array}$ \\
\hline $\begin{array}{c}\text { Acidic } \\
\text { hydrolysate } \\
\text { Enzymatic } \\
\text { hydrolysate }\end{array}$ & $11.70 \pm 0.48^{\mathrm{b}}$ & $7.70 \pm 0.37^{\mathrm{b}}$ & $0.90 \pm 0.05^{\mathrm{b}}$ & $34.58 \pm 2.00^{\mathrm{a}}$ \\
$\mathrm{a}, \mathrm{b}$ Values in a column for each sample are significantly different $(p<0.05)$. Initial glucose concentration was $40 \mathrm{~g} / \mathrm{L}$.
\end{tabular}

From the batch cultivation in the bioreactor, there were no lag phases in the first $24 \mathrm{~h}$ of both hydrolysate fermentations, which may be due to a sufficient oxygen supply. In the enzymatic hydrolysate fermentation, the specific growth rate and substrate consumption rate were both higher than those of glucose fermentation in the first $48 \mathrm{~h}$ (Figure 5). Moreover, the biomass concentration reached $15.02 \mathrm{~g} / \mathrm{L}$ in $48 \mathrm{~h}$, which was 1.61-fold of glucose fermentation. The maximum biomass concentration $(17.72 \mathrm{~g} / \mathrm{L})$ was found in $72 \mathrm{~h}$, and the carbon substrate composition was $537.22 \mathrm{mg} / \mathrm{L}-\mathrm{h}$. However, the biomass concentration was decreased after $72 \mathrm{~h}$, due to the lack of a carbon source. The dissolved oxygen (DO) level reached zero in $20 \mathrm{~h}$, indicating the high oxygen demand in the lag phase under enzymatic hydrolysate fermentation. Therefore, the agitation speed was increased to $250 \mathrm{rpm}$ after $20 \mathrm{~h}$ to maintain the DO level at around 20\%. In 60-72 h, the DO level reached zero again, and then the biomass concentration decreased, and $\mathrm{pH}$ increased, indicating the beginning of the decline phase. The results indicated the potential of enzymatic hydrolysate as a carbon source for M. alpina FU30797 fermentation.

From the fed-batch cultivation in the bioreactor, the enzymatic hydrolysate feed stock solution was added three times (at 50,74, and $98 \mathrm{~h}$ ) to maintain the concentration of the carbon substrate within 10-20 g/L at the desired levels during the 5 days of fermentation. Ji et al. found that small fungal mycelium pellets of uniform size could be obtained in a relatively lower glucose concentration (initially $25 \mathrm{~g} / \mathrm{L}$ glucose and repeated feed within $10-20 \mathrm{~g} / \mathrm{L}$ ), which is good fungal morphology for ARA production $[20,26]$. The final biomass concentration was $18.94 \mathrm{~g} / \mathrm{L}$, which is similar to that of the glucose batch study, but with a higher lipid content (36.97\%). Moreover, the ARA ratio (46.04\%) was higher than that of glucose batch study $(22.43 \%)$.

Vadivelan et al. evaluated the levels of biomass content, lipid content and ARA amount of the total fatty acid content, and found that they were 4.3-10.82 g/L, 29.07-41.02 g/L and $22.01-53.86 \%$, respectively, among 11 Mortierella strains [27]. The highest amount of total fatty acid content $(53.86 \%)$ and biomass $(10.82 \mathrm{~g} / \mathrm{L})$ were found in M. alpina CFR-GV15, and its lipid production was $4.32 \mathrm{~g} / \mathrm{L}$, which is slightly lower than that of enzymatic hydrolysate fermentation in this study. Nisha et al. investigated the influence of various nitrogen sources on M. alpina cultivation, and the maximum biomass $(6.8 \mathrm{~g} / \mathrm{L})$ and highest ARA content in lipids (35.28\%) were obtained by using yeast extract, and the lipid content reached $41 \%$ [7]. Zhang et al. reviewed the progress in enhancing $M$. alpina production by optimization of the culture medium, fermentation process and genetic modification [28], and Mortierella alpina ME-1, a UV mutant of ATCC 16266, showed the highest ARA productivity $(2.8 \mathrm{~g} / \mathrm{L}-\mathrm{d})$, with a 78\% ARA ratio, by applying improved mycelium aging technology [29]. Furthermore, the biomass, lipid content and ARA ratio of M. alpina F-23, a mutant strain, were $29.20 \mathrm{~g} / \mathrm{L}$, $38.79 \%$ and $50.36 \%$, respectively [30]. This research indicated that $M$. alpina is a promising source for ARA-rich lipid production; however, the economic efficiency could be affected by the strain availability, culture medium, fermentation strategy, harvest method and extraction technology. Song et al. used maize starch hydrolysate as a carbon source and soybean meal as the main nitrogen source for docosahexaenoic acid (DHA) production by Schizochytrium limacinum OUC88, and found that the utilization of these low-cost substrates will improve the economic and competitive efficiency of commercial DHA production [31]. In this study, TPW is a starch-rich agricultural waste, and the cost of the enzyme for 
producing a kilogram of carbon substrate (as glucose) is about USD 0.07. For sustainable development, this work demonstrates the feasibility of TPW hydrolysate as an alternative carbon substrate to glucose, and a cost reduction in culture medium might be expected.
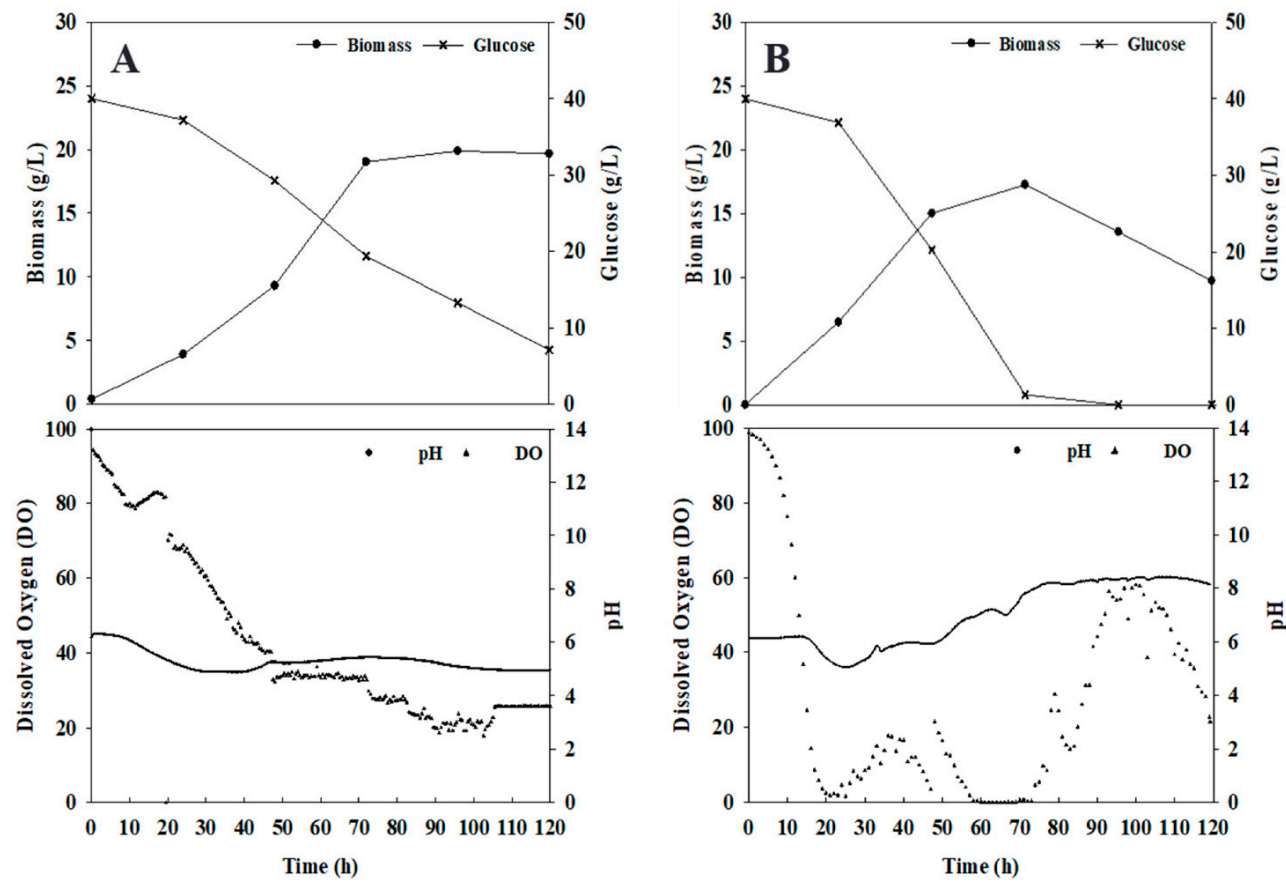

Figure 5. Biomass concentration, glucose consumption, $\mathrm{pH}$ and dissolved oxygen (DO) of Mortierella alpina FU30797 batch cultivation in the bioreactor with (A) glucose and (B) enzymatic hydrolysate for 5 days (initial carbon source (as glucose) concentration was $40 \mathrm{~g} / \mathrm{L}$ ).

\section{Conclusions}

This study found that M. alpina FU30797 was suitable for PUFA-ARA production, and confirmed that TPW acidic/enzymatic hydrolysate could be used as an alternative low-cost substrate for M. alpina FU30797 cultivation. In addition, the potential application of sea salt solution as a seawater replacement was suggested, in order to conserve fresh water resources. The results of this study could provide useful information for developing the valuable metabolites of the PUFA-ARA bioprocess from the perspective of biorefinery and sustainability.

Author Contributions: Conceptualization, supervision and project administration, Y.-H.C.; analysis and original draft preparation, Y.-H.C. and C.-C.O.; assisting part of experiments, C.-C.O. and T.-Y.L.; writing and editing, Y.-H.C. All authors have read and agreed to the published version of the manuscript.

Funding: This research was funded by the Ministry of Science and Technology, Taiwan, ROC. (MOST 105-2221-E-197-028-MY2).

Institutional Review Board Statement: Not applicable.

Informed Consent Statement: Not applicable.

Data Availability Statement: The data presented in this study are available in this article.

Acknowledgments: The authors gratefully acknowledge the financial support for this research by the Ministry of Science and Technology, Taiwan, ROC. (MOST 105-2221-E-197-028-MY2), and we also thank Yih Shun Shiuan Company (Yi-Lan, Taiwan) for providing taro waste.

Conflicts of Interest: The authors declare no conflict of interest. 


\section{References}

1. Rondanelli, M.; Giacosa, A.; Opizzi, A.; Pelucchi, C.; La Vecchia, C.; Montorfano, G.; Negroni, M.; Berra, B.; Politi, P.; Rizzo, A.M. Long chain omega 3 polyunsaturated fatty acids supplementation in the treatment of elderly depression: Effects on depressive symptoms, on phospholipids fatty acids profile and on health-related quality of life. J. Nutr. Health Aging 2011, 15, 37-44. [CrossRef] [PubMed]

2. Cicero, A.F.; Reggi, A.; Parini, A.; Borghi, C. Application of polyunsaturated fatty acids in internal medicine: Beyond the established cardiovascular effects. Arch. Med. Sci. 2012, 8, 784-793. [CrossRef] [PubMed]

3. Carlsson, J.A.; Wold, A.E.; Sandberg, A.S.; Ostman, S.M. The polyunsaturated fatty acids arachidonic acid and docosahexaenoic acid induce mouse dendritic cells maturation but reduce T-Cell responses in vitro. PLoS ONE 2015, 10, e0143741. [CrossRef] [PubMed]

4. Gill, I.; Valivety, R. Polyunsaturated fatty acids, Part 1: Occurrence, biological activities and applications. Trends Biotechnol. 1997, 15, 401-409. [CrossRef]

5. Chen, H.C.; Chang, C.C.; Chen, C.X. Optimization of arachidonic acid production by Mortierella alpina Wuji-H4 isolate. J. Am. Oil. Chem. Soc. 1997, 74, 569-578. [CrossRef]

6. Wu, W.J.; Zhang, A.H.; Peng, C.; Ren, L.J.; Song, P.; Yu, Y.D.; Huang, H.; Ji, X.J. An efficient multi-stage fermentation strategy for the production of microbial oil rich in arachidonic acid in Mortierella alpina. Bioresour. Bioprocess. 2017, 4, 8. [CrossRef] [PubMed]

7. Nisha, A.; Venkateswaran, G. Effect of culture variables on mycelial arachidonic acid production by Mortierella alpina. Food Bioprocess Technol. 2011, 4, 232-240. [CrossRef]

8. Wu, W.; Yan, J.; Ji, X.; Zhang, X.; Shang, J.; Sun, L.; Ren, L.; Huang, H. Lipid characterization of an arachidonic acid-rich oil producing fungus Mortierella alpina. Chin. J. Chem. Eng. 2015, 23, 1183-1187. [CrossRef]

9. Li, X.; Lin, Y.; Chang, M.; Jin, Q.; Wang, X. Efficient production of arachidonic acid by Mortierella alpina through integrating fed-batch culture with a two-stage $\mathrm{pH}$ control strategy. Bioresour. Technol. 2015, 181, 275-282. [CrossRef]

10. Cao, G.; Guan, Z.; Liu, F.G.; Liao, X.; Cai, Y. Arachidonic acid production by Mortierella alpina using raw crop materials. Acta Sci. Pol. 2015, 14, 133-143. [CrossRef]

11. Sun, D.; Zhou, C.; Zhu, C.; Sun, Y. Effects of culture medium on PUFAs production by Mortierella isabellinas. In Advances in Applied Biotechnology Proceedings of the 2nd International Conference on Applied Biotechnology (ICAB 2014)-Volume II; Zhang, T.-C., Nakajima, M., Eds.; Springer: Berlin/Heidelberg, Germany, 2015; pp. 219-228.

12. Hsieh, S.-C.; Liu, J.-M.; Pua, X.-H.; Ting, Y.; Hsu, R.-J.; Cheng, K.-C. Optimization of Lactobacillus acidophilus cultivation using taro waste and evaluation of its biological activity. Appl. Microbiol. Biotechnol. 2016, 100, 2629-2639. [CrossRef] [PubMed]

13. Arapoglou, D.; Varzakas, T.; Vlyssides, A.; Israilides, C. Ethanol production from potato peel waste (PPW). Waste Manag. 2010, 30, 1898-1902. [CrossRef] [PubMed]

14. Izmirlioglu, G.; Demirci, A. Ethanol production from waste potato mash by using Saccharomyces cerevisiae. Appl. Sci. 2012, 2, 738-753. [CrossRef]

15. Khawla, B.J.; Sameh, M.; Imen, G.; Donyes, F.; Dhouha, G.; Raoudha, E.G.; Oumèma, N.-E. Potato peel as feedstock for bioethanol production: A comparison of acidic and enzymatic hydrolysis. Ind. Crop. Prod. 2014, 52, 144-149. [CrossRef]

16. Dong, M.; Walker, T.H. Addition of polyunsaturated fatty acids to canola oil by fungal conversion. Enzyme Microb. Technol. 2008, 42, 514-520. [CrossRef]

17. Zeng, Y.; Ji, X.J.; Chang, S.M.; Nie, Z.K.; Huang, H. Improving arachidonic acid accumulation in Mortierella alpina through B-group vitamin addition. Bioprocess Biosyst. Eng. 2012, 35, 683-688. [CrossRef] [PubMed]

18. Sutanto, S.; Go, A.W.; Chen, K.-H.; Ismadji, S.; Ju, Y.-H. Maximized utilization of raw rice bran in microbial oils production and recovery of active compounds: A proof of concept. Waste Biomass Valorization 2016, 8, 1067-1080. [CrossRef]

19. Wu, W.H.; Hung, W.C.; Lo, K.Y.; Chen, Y.H.; Wan, H.P.; Cheng, K.C. Bioethanol production from taro waste using thermo-tolerant yeast Kluyveromyces marxianus K21. Bioresour. Technol. 2016, 201, 27-32. [CrossRef]

20. Ji, X.J.; Zhang, A.H.; Nie, Z.K.; Wu, W.J.; Ren, L.J.; Huang, H. Efficient arachidonic acid-rich oil production by Mortierella alpina through a repeated fed-batch fermentation strategy. Bioresour. Technol. 2014, 170, 356-360. [CrossRef] [PubMed]

21. Miller, G.L. Use of dinitrosalicylic acid reagent for determination of reducing sugar. Anal. Chem. 1959, 31, 426-428. [CrossRef]

22. Higashiyama, K.; Yaguchi, T.; Akimoto, K.; Fujikawaa, S.; Shimizu, S. Effects of mineral addition on the growth morphology of and arachidonic acid production by Mortierella alpina 1S-4. J. AOCS 1998, 75, 1815-1819. [CrossRef]

23. Ho, S.-Y.; Chen, F. Lipid characterization of Mortierella alpina grown at different $\mathrm{NaCl}$ concentrations. J. Agric. Food Chem. 2008, 56, 7903-7909. [CrossRef] [PubMed]

24. Song, X.; Ma, Z.; Tan, Y.; Zhang, H.; Cui, Q. Wastewater recycling technology for fermentation in polyunsaturated fatty acid production. Bioresour. Technol. 2017, 235, 79-86. [CrossRef]

25. Goyzueta-Mamani, L.D.; de Carvalho, J.C.; Magalhães, A.I., Jr.; Soccol, C.R. Production of arachidonic acid by Mortierella alpina using wastes from potato chips industry. J. Appl. Microbiol. 2021, 130, 1592-1601. [CrossRef]

26. Higashiyama, K.; Fujikawaa, S.; Park, E.Y.; Shimizu, S. Production of arachidonic acid by Mortierella fungi. Biotechonol. Bioprocess Eng. 2002, 7, 252-262. [CrossRef]

27. Vadivelan, G.; Venkateswaran, G. Production and enhancement of omega-3 fatty acid from Mortierella alpina CFR-GV15: Its food and therapeutic application. BioMed Res. Int. 2014, 2014, 657414. [CrossRef] [PubMed] 
28. Zhang, H.; Cui, Q.; Song, X. Research advances on arachidonic acid production by fermentation and genetic modification of Mortierella alpina. World J. Microbiol. Biotechnol. 2021, 37, 4. [CrossRef]

29. Jin, M.J.; Huang, H.; Xiao, A.H.; Gao, Z.; Liu, X.; Peng, C. Enhancing arachidonic acid production by Mortierella alpina ME-1 using improved mycelium aging technology. Bioprocess Biosyst. Eng. 2009, 32, 117-122. [CrossRef]

30. Zhang, H.; Lu, D.; Li, X.; Feng, Y.; Cui, Q.; Song, X. Heavy ion mutagenesis combined with triclosan screening provides a new strategy for improving the arachidonic acid yield in Mortierella alpina. BMC Biotechnol. 2018, 18, 23. [CrossRef]

31. Song, X.; Zang, X.; Zhang, X. Production of high docosahexaenoic acid by Schizochytrium sp. using low-cost raw materials from food industry. J. Oleo Sci. 2015, 64, 197-204. [CrossRef] 